\title{
Disease and Diagnosis
}

\section{The Effect of Follow ups with Weekly Phone Calls on the Outcome and Quality of Life Among the Patients with Rheumatoid Arthritis}

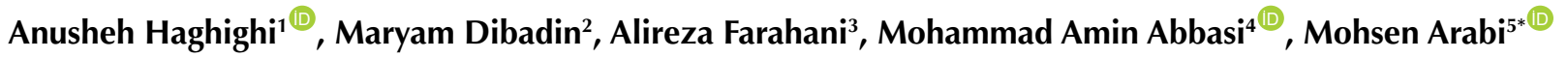 \\ ${ }^{1}$ Department of Rheumatology, Iran University of Medical Sciences, Tehran, Iran. \\ ${ }^{2}$ Department of Family Medicine, Firoozabadi Clinical Research Development Unit, Iran University of Medical Sciences \\ (IUMS), Tehran, Iran. \\ ${ }_{3}^{3}$ Firoozabadi Clinical Research Development Unit, Iran University of Medical Sciences, Tehran, Iran. \\ ${ }^{4}$ Department of Internal Medicine, Firoozabadi Clinical Research Development Unit, Iran University of Medical Sciences, \\ Tehran, Iran. \\ ${ }^{5}$ Preventive Medicine and Public Health Research Center, Family Medicine Department, Iran University of Medical \\ Sciences, Tehran, Iran.
}

\begin{abstract}
Background: The present study aimed at evaluating the effect of weekly phone calls on treatment outcomes and quality of life among a group of Iranian patients with rheumatoid arthritis (RA). Materials and Methods: In this randomized clinical trial study, 60 patients aged 15-85 with RA were randomly assigned to intervention and control groups. The intervention group, in addition to a monthly assessment on a weekly basis, received a full 3-month follow-up telephone conversation in order to follow the correct and regular use of the drug and respond to the patients' questions. The control group was only evaluated routinely. Finally, the severity of the disease activity (based on DAS-28) and the quality of life (based on the SF-12 questionnaire) were evaluated after three months.

Results: After three months from the onset of intervention, a significant reduction was observed in the number of tender joints, mean erythrocyte sedimentation rate (ESR), and total score of DAS-28 in the intervention group compared to the control group. In addition, after three months of treatment, the quality of life for the intervention group improved significantly more than that of the control group.

Conclusion: A weekly phone call with the patients suffering from RA with the purpose to guide the therapeutic process and respond to the patients' questions could positively improve the severity of the disease along with the quality of life among the patients.

Keywords: Rheumatoid arthritis, Phone, Quality of life
\end{abstract}

\author{
*Correspondence to \\ Mohsen Arabi, \\ Preventive Medicine and \\ Public Health Research \\ Center, Family Medicine \\ Department, Iran University \\ of Medical Sciences, \\ Tehran, Iran. \\ Tel: 09127667297 \\ Email: Drmohsenarabi@ \\ gmail.com
}

Received: March 18, 2021, Accepted: August 22, 2021, ePublished: September 30, 2021

\section{Introduction}

Rheumatoid arthritis (RA) is an autoimmune disorder. Genetic and environmental factors are risk factors associated with RA which is estimated to affect $0.25 \%$ to $1 \%$ of the world population. The role of a family doctor in the early diagnosis of RA and timely treatment is essential to obtain the best prognosis for any patient. A family doctor informs the patient and his family about the importance of using medications as the primary RA treatment method (1). In addition, several studies acknowledged that telephone communication may provide clinical advice and support for RA patients. Although these services cannot be a substitute for in-person clinical services, the patients should be encouraged to take both measures to have easy access to medical counseling and clinical practice optimization (2). Providing telephone services can improve the quality of the services provided by the outpatient wards, which results in saving costs and satisfying patients. Therefore, considering a wide range of RA diseases in all age groups, especially in the elderly, the lack of sufficient tolerance to receive long-term treatment, and the importance of treatment in the disease recovery, many patients abandon treatment due to an impression of recovery or fear of drug complications, leading to irremediable consequences for the patients. Accordingly, the importance of constant monitoring, continuous follow-up of the treatment, and following the doctor's recommendations can significantly

(C) 2021 The Author(s). This is an open access article distributed under the terms of the Creative Commons Attribution License (http:// creativecommons.org/licenses/by/4.0/), which permits unrestricted use, distribution, and reproduction in any medium, provided the original work is properly cited. 
influence the long-term disease progression (3).

A large number of studies have focused on the impact of telephone contact and follow-up of RA patients on the service quality and faster disease recovery. For example, providing a 15-minute drug consultation or sending a reminder phone call to the patients could increase the follow-through and adherence of patients to the treatment and enhance the patients' satisfaction with the treatment process (1). A multi-center study in England found that RA patients considered the established communication benefits and the value of social-communicatory emotional support to be beyond clinical interactions, which could increase their participation in the treatment (4). In addition, telephone counseling with a physician and a nurse rather than on-site visits resulted in easier and better access to contact with the nurse, leading to overall satisfaction with the provided treatment (5). In another study, making phone calls was found to be as effective as a physical presence at the clinic in relieving the pain and clinical symptoms of RA patients 6-12 months after the treatment onset (6).

Based on the evidence, making phone calls for providing counseling services to patients and managing their therapeutic process can play a significant role in controlling the recovery of RA patients, improving their satisfaction levels, and reducing the financial burden associated with patient care provision. However, no study, to the best of our knowledge, has addressed this issue in Iran. Thus, the present study strived to evaluate the effect of weekly phone calls on the treatment outcomes and quality of life in a selected sample of Iranian patients with RA.

\section{Materials and Methods}

This study is an intervention semi-experimental study in which 60 RA patients aged 15-85 years who had referred to Rasoul-e-Akram super-specialty hospital were randomly selected to be involved in this clinical trial. In addition, all of the patients had final RA as diagnosed by the hospital rheumatologists. Those who were not interested in making phone calls and had no active monthly visits to the clinic were excluded from the study. Then, the patients were randomly assigned to intervention and control groups based on the randomized numerical table. In addition to the monthly assessments per week, the intervention group received a 3-month telephone call (a total of 12 contacts per patient within three months) and was under full supervision in order to track the correct and regular drug use and respond to the patients' questions regarding the treatment procedure. The control group was only evaluated monthly in person for three months. All of the monthly clinical examinations and requests for relevant tests were performed by the rheumatologists at the clinic. The average time for telephone calls was fifteen minutes. The question asked were about the amount, time, and type of the prescribed drugs, and the patients were given necessary training in these regards. In addition, two questionnaires were used to evaluate the subjects in both groups before and after the study. First, DAS-28 was used as a standard instrument for assessing disease activity and severity in RA patients. Then, the number of painful and swollen joints, the amount of erythrocyte sedimentation rate (ESR), and the final score of the disease severity were considered for calculating the score. The scores of 0-2.6, 2.7-3.2, 3.3-5.1, and higher than 5.1 were considered as optimal disease recovery and control, mild activity, moderate disease activity, and acute disease activity, respectively. In addition, the quality of life questionnaire (SF-12) including 12 questions was utilized to assess the overall patient's understanding of his/her health, physical functioning, physical health, emotional problems, physical pain, social function, vitality and energy, and mental health. In this questionnaire, higher scores represent a more desirable level of quality of life in patients, and general health status is recorded from zero as the worst to 100 as the best health conditions for patients. Items of the SF-12 questionnaire were already confirmed by Arabi et al in a study conducted among Iranian patients (7). The reliability and validity of this questionnaire were 0.9 and 0.95 , respectively. In the present study, the changes in disease severity and the quality of life scores in patients were compared between the two groups before and after the intervention.

T-test and/or Mann-Whitney tests were used for analyzing the data related to quantitative variables, and the Chi-square test was used to compare qualitative variables at the significance level of 0.05 .

\section{Results}

In this study, 60 patients with complete records were selected based on the number of active files in the rheumatic clinic of Rasoul-e-Akram super-specialty hospital in Tehran. They were randomly divided into intervention and control groups $(n=30)$. As displayed in Table 1, no difference was observed between the two

Table 1. Comparison of Underlying Characteristics Between Intervention and Control Groups

\begin{tabular}{|c|c|c|c|}
\hline Characteristics & $\begin{array}{c}\text { Intervention } \\
\text { Group } \\
(\mathbf{n}=\mathbf{3 0})\end{array}$ & $\begin{array}{c}\text { Control } \\
\text { Group } \\
(n=30)\end{array}$ & P Value \\
\hline Average age (y) & $52.4 \pm 30.1$ & $55.9 \pm 2.61$ & 0.379 \\
\hline \multicolumn{4}{|l|}{ Gender, No. (\%) } \\
\hline Male & $7(23.3)$ & $8(26.6)$ & \multirow{2}{*}{0.998} \\
\hline Female & $23(76.7)$ & $22(73.4)$ & \\
\hline \multicolumn{4}{|l|}{ Level of education, No. (\%) } \\
\hline Primary school and lower & $2(6.7)$ & $6(20.0)$ & \multirow{3}{*}{0.122} \\
\hline Guidance and high school & $2(6.7)$ & $5(16.7)$ & \\
\hline Diploma and higher & $26(86.6)$ & $19(63.3)$ & \\
\hline
\end{tabular}


groups in terms of gender, mean age, and education level. In addition, no significant difference was reported in terms of the disease activity characteristics such as the number of painful and swollen joints and ESR levels before the intervention (Table 2). However, after three months of intervention, the number of painful joints, mean ESR, and total scores of DAS-28 decreased significantly among the patients in the intervention group compared to the control group. Although no difference was found between the two groups regarding the quality of life scores before intervention (Table 3), the quality of life in the intervention group improved significantly after three months of intervention as compared with the control group.

\section{Discussion}

The present study sought to find out whether there is any significant difference after the three-month intervention based on the improvement in RA severity and patients' quality of life. The results indicated that the improvements in the disease severity/activity in terms of painful joints, mean ESR, and the total score of the disease severity/activity in the intervention group with telephone contact and follow-up were significantly higher than those received routine treatment (i.e., the control group). Further, the quality of life improved among the patients in the intervention group compared to those in the control group. The results are consistent with the study conducted by Mary et al (1), focusing on the effect of weekly text messages (SMS) on adherence to treatment and health satisfaction in RA patients using methotrexate. They found that a 15-minute drug counseling or receiving a reminder SMS with standard counseling could result in improving disease manifestations as well as the patients' satisfaction of health and quality of life (1). However, the Compliance-Questionnaire-Rheumatology (CQR-19) was used for assessing the quality of life and a 6-month follow-up period in the present study. In another study, the effectiveness of motivational counseling and SMS reminder was evaluated among 150 patients. Followup evaluations after 6 and 18 months of intervention indicated that a simple and noninvasive intervention led to improvements in the physical pain and quality of life, along with a reduction in the therapeutic costs (8). Further, 1036 patients were evaluated for 6-12 months at the clinic or by telephone. The results revealed that the pain decreased among the patients who were followed up at the clinic with telephone follow-up for 6-12 months (6). Additionally, the effect of a short-term motivational intervention through phone calls was considered to evaluate the effect of cognitive and behavioral coping and psychological stressors through chronic pain during 9 months. The results indicated the positive effects of cognitive coping in the intervention group (9). In another study, short-term telephone-based drug counseling among RA patients was found to be associated with the reduction of total costs for the healthcare provider (10). Finally, no drug discontinuation was reported among RA patients by using a centralized telephone service at home (11). In conclusion, the use of information and

Table 2. Comparison of Joint Involvement Indices in Intervention and Control Groups

\begin{tabular}{|c|c|c|c|}
\hline Characteristics & $\begin{array}{c}\text { Intervention Group } \\
(95 \% \mathrm{CI})\end{array}$ & $\begin{array}{l}\text { Control Group } \\
(95 \% \mathrm{CI})\end{array}$ & $P$ Value \\
\hline \multicolumn{4}{|l|}{ Joint swelling } \\
\hline Before intervention & $(4.0-6.9) 5.5$ & $(3.1-5.3) 4.2$ & 0.171 \\
\hline One month later & $(0.0-3.0) 2.1$ & $(1.0-4.0) 2.7$ & 0.549 \\
\hline Two months later & $(0.0-3.0) 1.8$ & $(0.0-2.0) 1.7$ & 0.939 \\
\hline Three months later & $(0.03-2.0) 1.2$ & $(0.0-2.0) 1.6$ & 0.186 \\
\hline \multicolumn{4}{|l|}{ Painful joint } \\
\hline Before intervention & $(8.3-12.1) 10.3$ & $(6.2-9.1) 7.7$ & 0.340 \\
\hline One month later & $(2.0-6.0) 4.7$ & (3.0-6.0) 5.0 & 0.346 \\
\hline Two months later & (1.0-4.0) 3.1 & $(2.0-5.0) 4.1$ & 0.094 \\
\hline Three months later & $(0.0-3.0) 2.1$ & $(2.0-5.0) 3.7$ & 0.011 \\
\hline \multicolumn{4}{|l|}{ Average ESR } \\
\hline Before intervention & (21.3-39.8) 30.6 & $(23.5-39.2) 31.4$ & 0.890 \\
\hline One month later & (10.8-20.0 15.2 & (15.7-28.8) 22.00 & 0.137 \\
\hline Two months later & (7.0-0.19) 13.4 & (14.0-25.0) 20.0 & 0.017 \\
\hline Three months later & $(5.0-11.0) 8.6$ & (15.0-24.0 19.0 & 0.001 \\
\hline \multicolumn{4}{|l|}{ DAS-28 score } \\
\hline Before intervention & $(4.3-4.9) 4.6$ & $(4.0-4.7) 4.3$ & 0.231 \\
\hline One month later & $(2.3-3.3) 2.8$ & (2.8-3.9) 3.3 & 0.440 \\
\hline Two months later & (1.8-2.9) 2.4 & $(2.5-3.5) 3.0$ & 0.292 \\
\hline Three months later & (1.4-2.3) 1.8 & $(2.5-3.4) 2.9$ & 0.001 \\
\hline
\end{tabular}

Note. Cl: Confidence interval; ESR: Erythrocyte sedimentation rate. 
Table 3. Mean Score of Patients' Quality of Life Before and After Treatment in Both Intervention and Control Groups

\begin{tabular}{cccc}
\hline Characteristics & $\begin{array}{c}\text { Intervention Group } \\
(\mathbf{9 5} \% \mathbf{C l})\end{array}$ & $\begin{array}{c}\text { Control Group } \\
(\mathbf{9 5} \% \mathbf{C l})\end{array}$ & $\boldsymbol{P}$ Value \\
\hline Before intervention & $(23.8-26.5) 25.2$ & $(21.2-24.9) 23.1$ & 0.712 \\
Three months later & $(35.0-38.1) 36.8$ & $(22.0-25.9) 23.9$ & 0.001 \\
\hline
\end{tabular}

Note. $\mathrm{Cl}$ : Confidence interval.

reminder methods via telephone or messaging resulted in improving the treatment and disease control.

It should be noted that the present study suffered from some limitations such as a limited number of active and complete cases. In the present study, just four visits occurred. In addition, the general quality of life questionnaire was used rather than specialized tools for assessing the quality of life in RA patients. Based on these limitations, more accurate results can be obtained from the effect of telephone contacts on improving patients' therapeutic status by using a larger sample size, extended follow-up periods, more consecutive follow-up visits, as well as the use of specialized quality of life tools.

\section{Conclusion}

Based on the results, weekly phone contacts with RA patients could positively influence the quality of life in patients, which can be taken into account in implementing routine treatment plans and controlling the general health of patients.

\section{Conflict of Interest Disclosures}

The authors declare no conflict of interests.

\section{Acknowledgments}

The authors are grateful to the clinic Rasoul-e-Akram Hospital in Tehran for their assistance in data collection.

\section{Ethical Statement}

This study was approved by the Ethics Committee of Iran University of Medical Sciences, Iran (the study code: IR.IUMS. FMD.RE-1396.9511710004-13.20.7531).

\section{Authors' Contributions}

Study concept and design: AH; Analysis and interpretation of data: MA; The others collected data.

\section{Funding/Support}

The present study was financially supported by Iran University of Medical Sciences.

\section{Informed Consent}

Informed consent forms were completed by the patients.

\section{References}

1. Mary A, Boursier A, Desailly Henry I, Grados F, Séjourné A, Salomon S, et al. Mobile phone text messages and effect on treatment adherence in patients taking methotrexate for rheumatoid arthritis: a randomized pilot study. Arthritis Care Res (Hoboken). 2019;71(10):1344-52. doi: 10.1002/ acr.23750.

2. Rakel RE, Rakel D. Textbook of Family Medicine. 9th ed. Saunders; 2015.

3. Fauci AS. Harrison's Principles of Internal Medicine. McGraw-Hill Education; 2015.

4. Goodwin VA, Paudyal P, Perry MG, Day N, Hawton A, Gericke $\mathrm{C}$, et al. Implementing a patient-initiated review system for people with rheumatoid arthritis: a prospective, comparative service evaluation. J Eval Clin Pract. 2016;22(3):439-45. doi: 10.1111/jep.12505.

5. Vinall-Collier K, Madill A, Firth J. A multi-centre study of interactional style in nurse specialist- and physicianled Rheumatology clinics in the UK. Int J Nurs Stud. 2016;59:41-50. doi: 10.1016/j.ijnurstu.2016.02.009.

6. Gärtner M, Fabrizii JP, Koban E, Holbik M, Machold LP, Smolen JS, et al. Immediate access rheumatology clinic: efficiency and outcomes. Ann Rheum Dis. 2012;71(3):3638. doi: 10.1136/annrheumdis-2011-200315.

7. Arabi S RM, Sahaf R. Reliability and Validity of Persian version of SF-12 questionnaire among diasble patients. Pajouhandeh. 2014;98;2:91-8. [Persian].

8. Esbensen BA, Thomsen T, Hetland ML, Beyer N, Midtgaard J, Løppenthin $\mathrm{K}$, et al. The efficacy of motivational counseling and SMS-reminders on daily sitting time in patients with rheumatoid arthritis: protocol for a randomized controlled trial. Trials. 2015;16:23. doi: 10.1186/s13063-014-0540-x.

9. Rau J, Ehlebracht-König I, Petermann F. [Impact of a motivational intervention on coping with chronic pain: results of a controlled efficacy study]. Schmerz. 2008;22(5):575-78. doi: 10.1007/s00482-008-0658-4. [German].

10. Elliott RA, Barber N, Clifford S, Horne R, Hartley E. The cost effectiveness of a telephone-based pharmacy advisory service to improve adherence to newly prescribed medicines. Pharm World Sci. 2008;30(1):17-23. doi: 10.1007/s11096-007-9134-y.

11. Clifford S, Barber N, Elliott R, Hartley E, Horne R. Patientcentred advice is effective in improving adherence to medicines. Pharm World Sci. 2006;28(3):165-70. doi: 10.1007/s11096-006-9026-6. 